\title{
Self-heating mortars with using graphene oxide and increasing CSH gel formation with the direct current application
}

\author{
İsmail Hocaoğlu*(i) 1 \\ 1 Deparment of Civil Engineering, Afyon Kocatepe University, Afyonkarahisar (Turkey), ihocaoglu@aku.edu.tr \\ *Correspondence: ihocaoglu@aku.edu.tr
}

Received: 10.03.2021; Accepted: 03.12.2021; Published: 31.12.2021

Citation: Hocaoğlu, I. (2021). Self-heating mortars with using graphene oxide and increasing CSH gel formation with the direct current application. Revista de la Construcción. Journal of Construction, 20(3), 559-575. https://doi.org/10.7764/RDLC.20.3.559.

\begin{abstract}
Graphene oxide (GO) is that the product of the exfoliation of graphite by chemical processes. GO has a potential candidate to be used as a nano reinforcement material in cement-based systems due to its water dispensability, quite good mechanical properties, and high aspect ratios. In this research, the effects of different water/binder (water/cement) ratio $(0.55,0.70,0.90$, and 1.00) and graphene oxide on mortars to which applied DC stress intensity have been investigated. In experiments, $4 \mathrm{~cm} \times 4 \mathrm{~cm} \times 16 \mathrm{~cm}$ wood molds (electrical isolated) have been used. Immediately after mixing into the mixtures, a stress intensity of $25 \mathrm{~V}$ was applied for 24 hours with a DC power source. Experiments were conducted in the laboratory conditions. Effect on hydration internal temperatures of the mortars with direct current application has been investigated. It is also researched that, the effect of graphene oxide on hydration temperature by direct current (DC) application on mortars. Through the application of $25 \mathrm{~V}$ DC to the 300 dosage mortars to which have different w/c ratios $(0.55$, $0.70,0.90$ and 1.00), their internal temperatures are increased as $1.26{ }^{\circ} \mathrm{C}, 1.78{ }^{\circ} \mathrm{C}, 4.25$, and $3.30{ }^{\circ} \mathrm{C}$, respectively. When they are compared to the same water/cement ratio of reference samples, it has been observed that, when $0.025 \%$ ratio of graphene oxide has been added to admixture and also direct current has applied, hydration temperature values of mortars have been increased. Microscope views have been investigated from 300 dosage mortars whose w/c ratio is 0.90 and it is determined that CSH gel formation increases as using $0.025 \% \mathrm{GO}$ and DC stress intensity application. It is concluded that hydration reactions can be accelerated by applying electric current to the mortar and adding graphene oxide to the mixture.
\end{abstract}

Keywords: self-heating, graphene oxide, direct current, hydration time, mortar.

\section{Introduction}

Cement-based composite materials constitute the foremost preferred building materials in structures. Today, high-performance materials are needed. Nanotechnology products provide innovation in cement-based mortars and concrete by adding a new vision to building materials. It has emerged with the development of nanotechnology in nanoscale materials used to improve the durability and mechanical properties of cement-based materials (Sobolev \& Shah, 2015; Sanchez \& Sobolev, 2010; Li et al., 2016). Recent studies (Singh et al., 2011) concluded that GO is homogeneously distributed in the cement matrix. GO also has high tensile strength, optimum aspect ratio, and large surface area values in cement-based materials (Xu $\&$ Gao, 2011; Pan et al., 2015). Some investigations show that using nanoparticles in the cement-based systems can accelerate the hydration reaction in Portland cement (Chen et al., 2011; Makar \& Chan, 2009). Some researchers have investigated that 
the effect of carbon in cement-based materials. The following conclusion was reached: By adding nanotubes to cement-based materials, it can accelerate the formation of $\mathrm{CSH}$ and $\mathrm{Ca}(\mathrm{OH})_{2}$, which are the hydration products of cement (Makar \& Chan, 2009). Another feature of nano-sized materials is that they reduce the formation of microcracks (Chintalapudi et al., 2020). Akarsh and Bhat (2021) added GO at the rates of $0.05 \%, 0.10 \%, 0.15 \%$, and $0.20 \%$ by weight instead of cement. It was observed that the machinability properties of the samples decreased gradually with the increase in GO by weight. Jing et al. (2019) with their research; It was concluded that when $0.030 \%$ graphene oxide was added to the cement mortar instead of cement, the compressive strength increased by $9 \%$.

There have been some researches investigating the electrical properties of cement-based mortars. Uygunoglu et al. (2019) concluded that the mechanical properties of historical mortars could be determined by using electrical resistivity methods. Conventional cement-based materials are electrically insulating, mainly when dry (Shuya et al., 2020). Therefore, in cementbased composites, Electrical conductivity is achieved primarily by ion transport through the pore solution in the cement-based material. It is of great importance to evaluate the hydration process of cement-based materials at an early stage (Xiao et al., 2007; Schwarz et al., 2007). Recently, it's expected that the cement-based system's electrical conductivity and resistivity can be improved significantly by adding GO. Despite a lot of effort focused on graphene-cement composite research (Peyvandi et al., 2013; Alkhateb et al., 2013; Du \& Pang, 2015; Jing et al., 2017), few studies are reported on the electrical properties of graphene-cement composites.

This study is important because both the addition of $\mathrm{GO}$ and the application of direct current to the mortars, the $\mathrm{CH}$ and $\mathrm{CSH}$ gels in the microstructure of the mortars are formed tighter and faster.

\section{Description of the problem}

Today, materials are produced with nanotechnology, which are new products as a result of the development of technology. The use of nanotechnology in cement-based binders has brought great innovation in recent years. Some materials produced with nanotechnology, such as graphene oxide, increase the hydration temperature by replacing cement with cement-based composites. Increasing the hydration temperature of the cement-based composite shortens the setting time without losing any strength. In addition, since the amount of cement in the mixture will decrease, this study is important in terms of environmental pollution. This study is aimed to shorten the mold removal time by adding GO to the cement-based composite and applying direct current.

\section{Materials and methods}

\subsection{The material used and their properties/features}

In preparing the mortars, CEM I 42,5 R type cement, which is produced by Afyonkarahisar Cement Industry Factory, by TS EN 197-1, was used as a cement (EN 197-1, 2011). The proportions of $\mathrm{C}_{3} \mathrm{~S}, \mathrm{C}_{2} \mathrm{~S}, \mathrm{C}_{3} \mathrm{~A}$ and $\mathrm{C}_{4} \mathrm{AF}$ in the cement are 60.11 $\%, 11.02 \%, 6.97 \%$, and $9.95 \%$, respectively, and are shown in Table 1. Potable water was utilized in the mortar mixture. Mortars have been designed as crushed sand $(0-4 \mathrm{~mm})$, crushed stone. The specific gravity of crushed sand was determined as 2.68 . 
Table 1. Physical and chemical features of cement.

\begin{tabular}{cc}
\hline Content, \% & CEM I 42,5 R \\
\hline $\mathrm{CaO}$ & 63.60 \\
$\mathrm{SiO}_{2}$ & 19.60 \\
$\mathrm{Al}_{2} \mathrm{O}_{3}$ & 4.71 \\
$\mathrm{Fe}_{2} \mathrm{O}_{3}$ & 3.26 \\
$\mathrm{MgO}$ & 1.89 \\
$\mathrm{Na}_{2} \mathrm{O}$ & 0.33 \\
$\mathrm{~K}_{2} \mathrm{O}$ & 1.03 \\
$\mathrm{SO}_{3}$ & 4.62 \\
$\mathrm{Cr}_{2} \mathrm{O}_{3}$ & 0.03 \\
$\mathrm{TiO}_{2}$ & 0.39 \\
$\mathrm{KK}^{\text {Specific weight }}$ & 2.69 \\
Fineness, cm $/ \mathrm{g}$ & 3.10 \\
\hline
\end{tabular}

\subsection{Production of graphene oxide}

The stepwise synthesis process is given as follows (Marcano et al., 2010); Graphite powder (3 g) and Potassium permanganate $\left(\mathrm{KMnO}_{4}\right)(2 \mathrm{~g})$ is mixed in $360 \mathrm{~mL}$ of Sulphuric acid $\left(\mathrm{H}_{2} \mathrm{SO}_{4}\right)(98 \%)$, and $40 \mathrm{~mL}$ of Phosphoric acid $\left(\mathrm{H}_{3} \mathrm{PO}_{4}\right) \mathrm{kept}$ under at $5{ }^{\circ} \mathrm{C}$ with continuous stirring. The mixture is then stirred at $5{ }^{\circ} \mathrm{C}$ for 12 hours; then, the solution is cooled. Ice water and $4 \mathrm{ml}$ hydrogen peroxide $\left(\mathrm{H}_{2} \mathrm{O}_{2}\right)$ are added very slowly to the suspension and stirred continuously. The rate of addition of $\mathrm{H}_{2} \mathrm{O}_{2}$ is carefully controlled to keep the reaction temperature below $15^{\circ} \mathrm{C}$. Initially, the mango color of the solution is obtained. The mixture is stirred for approximately one hour at $5-10{ }^{\circ} \mathrm{C}$ until the color turns brown. For purification, the mixture is washed with $200 \mathrm{ml}$ of deionized water. It is then filtered by the mixture of $80 \%$ of water $\left(\mathrm{H}_{2} \mathrm{O}\right)$ and $20 \%$ of Hydrochloric acid (HCI) and then filtered by $70 \mathrm{ml}$ of ethanol. After filtration and drying at room conditions, the GO flakes are obtained as a powder. Finally, Graphene Oxide flakes are converted into few-layer sheets by ball milling for a duration of 15 hours. Peaks of hydroxyl, carboxylic acid, and alkoxy and epoxy were observed in the FTIR (Fourier transform infrared spectroscopy) spectrum of graphene oxide (Figure 1). At $1715 \mathrm{~cm}^{-1}$, the $\mathrm{C}=\mathrm{O}$ stretch belonging to the carboxylic acid groups and the $\mathrm{O}-\mathrm{H}$ stretch belonging to the hydroxyl groups at $3123 \mathrm{~cm}^{-1}$ was observed. The C-O stress belonging to the epoxy group was observed at $1220 \mathrm{~cm}^{-1}$. It has been observed that the C-O stress belonging to the alkoxy groups also peaked at $1045 \mathrm{~cm}^{-1}$. The results obtained coincide with the research conducted by Tiyek et al. (2016). Alma et al. (2017), in XRD (X-ray diffraction) spectroscopy analysis, a peak of $2 \theta=12.55^{\circ}$ was detected for GO. In this study, as a result of XRD analysis, a peak of $2 \theta=$ $12.60^{\circ}$ and a peak of $2 \theta=26.30^{\circ}$ was observed for GO (Figure 2). According to previous research, the second peak is thought to be graphite Lu \& Ouyang, 2017). These observed peaks indicate that graphene oxide was formed.

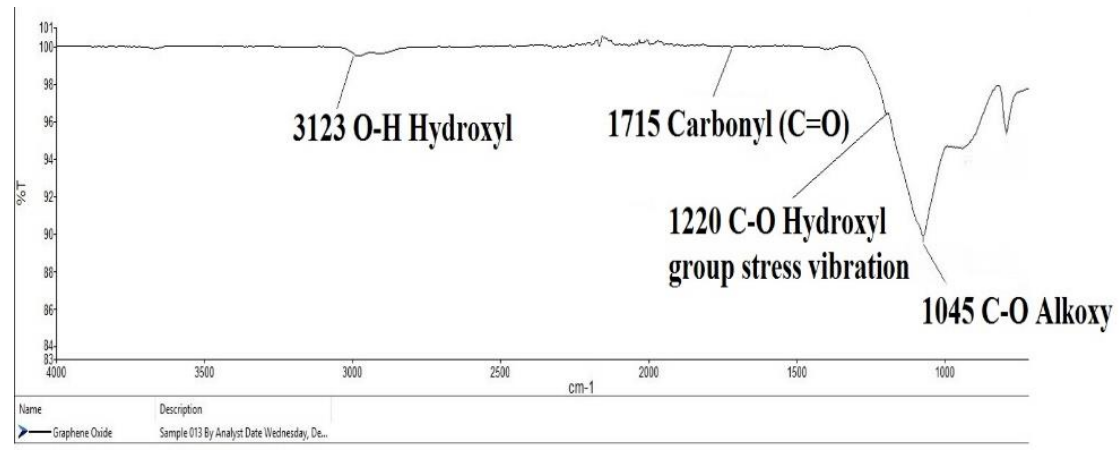

Figure 1. FTIR (Fourier transform infrared spectroscopy) spectrum of graphene oxide. 


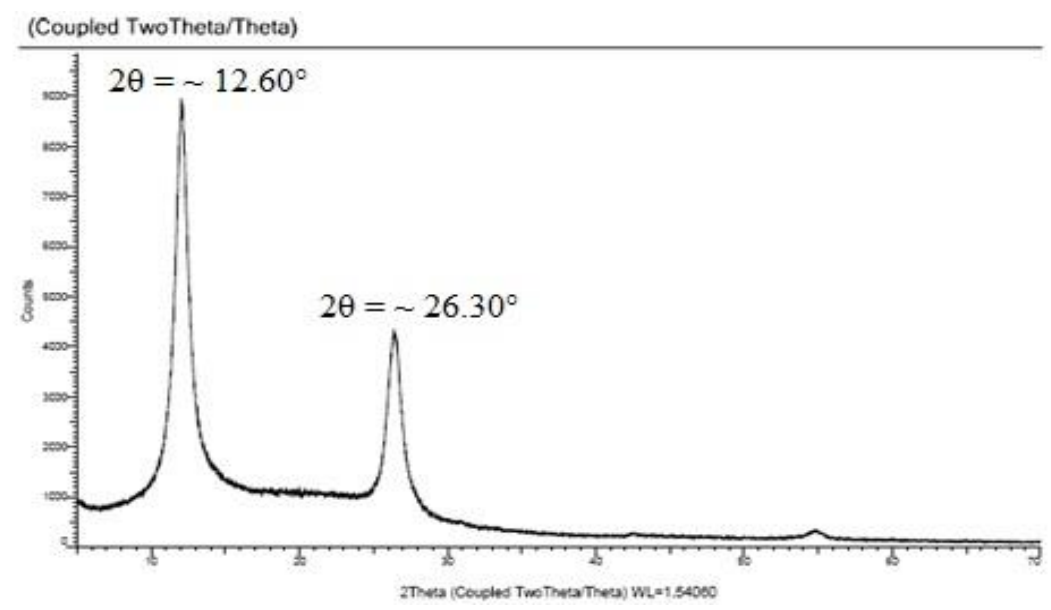

Figure 2. XRD (X-ray diffraction) spectroscopy analysis of graphene oxide.

\subsection{Production of the specimen and the experiments conducted}

Mortar production with 300 dosages; the w/c ratio was designed as $0.55,0.70,0.90,1.00$, and it was carried out with a concrete mixer with a capacity of 250 liters. While the mortar was being produced, first, the dry mixture was made (cement, aggregate and, graphene oxide), and then the admixture was mixed with water for 5 minutes. Cement (OPC), aggregate and graphene oxide (GO) are demonstrated in figure 1. Prepared mortars were placed in wood molds of $4 \mathrm{~cm} \mathrm{x} 4 \mathrm{~cm} \times 16 \mathrm{~cm}$ dimensions. The component of mortar per cubic meter is shown in Table 2. Mixture calculations have been prepared by determining the saturated surface dry weights of the coarse aggregate. The ratio of $0.025 \%$ graphene oxide has been added to the mortar mixtures. The amounts of cement, fine aggregate, and graphene oxide used in mortars are shown in Table 2.

Table 2. Component of mortar per cubic meter.

\begin{tabular}{ccccc}
\hline \multicolumn{5}{c}{ Mortar mixture ratio } \\
\hline W/c & Cement, $\mathrm{kg} / \mathrm{m}^{3}$ & Aggregate, $\mathrm{kg} / \mathrm{m}^{3}$ & Graphene oxide, $\mathrm{kg} / \mathrm{m}^{3}$ & Water, $1 \mathrm{t} / \mathrm{m}^{3}$ \\
\hline 0.55 & 300 & 1891.10 & - & 165.00 \\
0.70 & 300 & 1790.40 & - & 210.40 \\
0.90 & 300 & 1631.20 & - & 270.40 \\
1.00 & 300 & 1551.20 & - & 300.00 \\
0.55 & 299.92 & 1891.10 & 0.075 & 164.95 \\
0.70 & 299.92 & 1790.40 & 0.075 & 209.94 \\
0.90 & 299.92 & 1631.20 & 0.075 & 269,92 \\
1.00 & 299.92 & 1551.20 & 0.075 & 299,92 \\
\hline
\end{tabular}

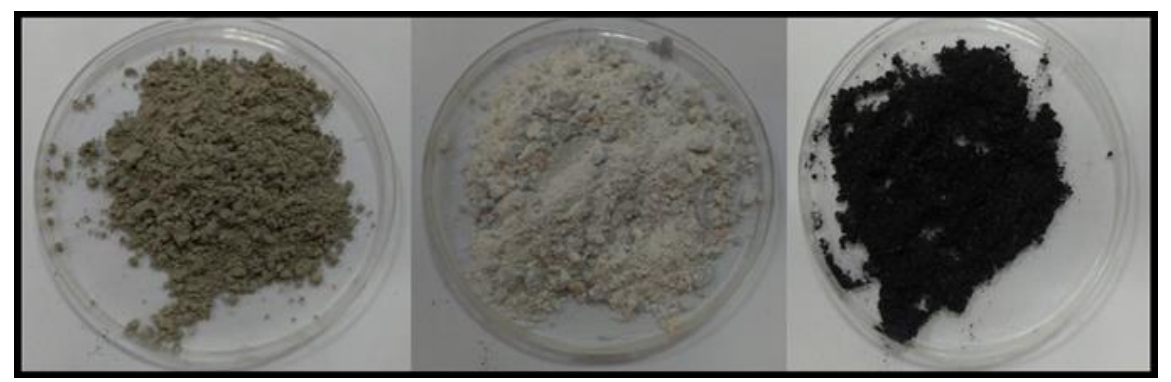

(a)

(b)

(c)

Figure 1. A view of (a) cement; (b) aggregate; (c) graphene oxide which have been used in experiments.

After the prepared mortars were placed in $4 \mathrm{~cm} \mathrm{x} 4 \mathrm{~cm}$ x $16 \mathrm{~cm}$ wood molds. The samples were kept in room condition for one day, and then they were removed from the molds and are cured in water saturated with lime for 28 days. DC power supply, 
whose capacity is $30 \mathrm{~V}$, has been used to apply electrical current on mortars for 24 hours. $25 \mathrm{~V}$ DC stress intensity has been applied on mortars. A computer has been used for saving internal temperature values of mortars during hydration reactions occur. Data have been recorded every 60 seconds. A view of the test setup mechanism has been shown in Picture 2.

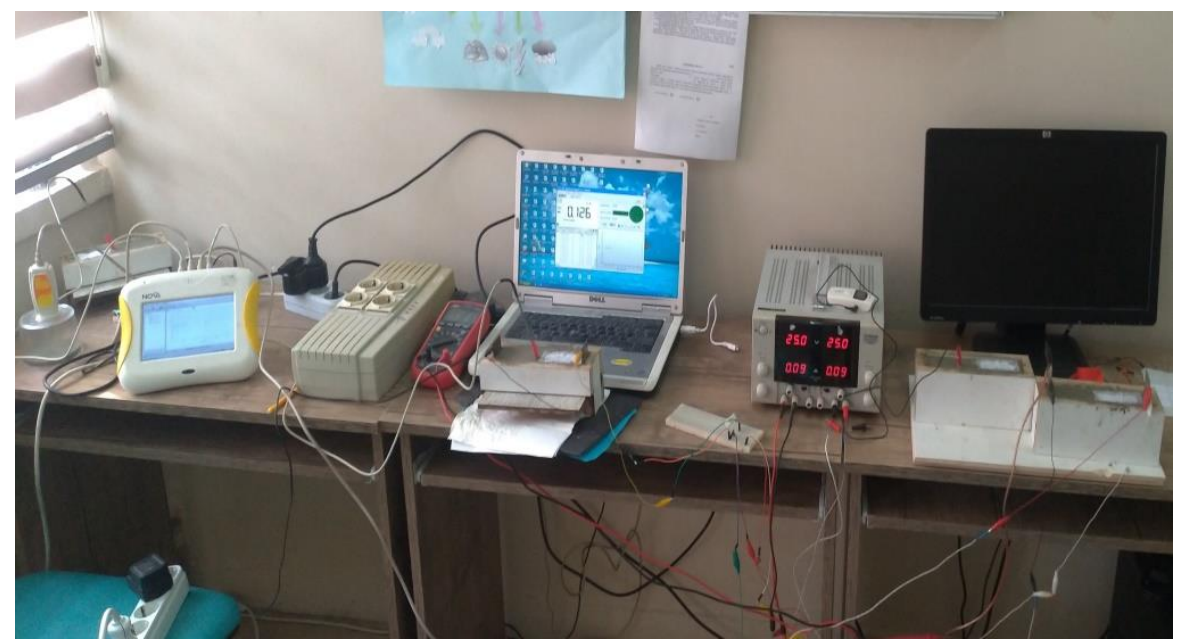

Figure 2. Applying DC to mortars and recording internal temperature values.

4. Experimental results and analysis

\subsection{Comparison of hydration temperatures in mortars containing and without $G O$}

As a result of some researches, it has been reached that the final setting time can be predicted by measuring the internal temperature of cement-based materials (Wade et al., 2010). It is observed that when the w/c ratio increases on mortars, the final setting time decreases (Figure 1). Increasing the temperature of cement-based systems increases the ion mobility within the cement and increases the electrical resistivity and vice versa (Tomlinson et al., 2017). According to the Arrhenius equations, the resistance of the cement-based material can be estimated between 10 and 45 degrees using the maturity method in ASTM C1074 (ASTM, 2015). When the internal temperature of the mortar increases, hydration reactions are also accelerated. Although hydration reactions accelerate in cement-based materials until the internal temperature reaches $100{ }^{\circ} \mathrm{C}$, some studies show that cement-based composites' ideal internal temperature range is $45-50{ }^{\circ} \mathrm{C}$ without loss of compressive strength (Luo et al., 2017). It is observed that as the w/c ratio increase and using GO in admixture on mortars, maximum internal temperatures of mortars increase, too. The highest internal temperatures of cement-based mortars with water-cement ratios of 0.55 , $0.70,0.90$, and 1.00 without graphene oxide were measured as $23.00{ }^{\circ} \mathrm{C}, 22.20^{\circ} \mathrm{C}, 22.50$, and $22.00{ }^{\circ} \mathrm{C}$, respectively (Figure 3 ). It was determined that the internal temperature increases of mortars whose water/cement ratios are $0.55,0.70,0.90$, and 1.00 from the beginning of hydration increased by $4.30{ }^{\circ} \mathrm{C}, 3.00{ }^{\circ} \mathrm{C}, 2.40$, and $3.30^{\circ} \mathrm{C}$, respectively. Kjaernsmo et al. (2018) added $0 \%, 0.02 \%, 0.03$, and $0.05 \% \mathrm{GO}$ to cement-based mortars, respectively, and they obtained the maximum internal temperature in mortars with $0.02 \% \mathrm{GO}$. In this study, $0.025 \% \mathrm{GO}$ was added to the mortars. As a result of adding $0.025 \%$ $\mathrm{GO}$ in the same w/c ratio mortars, the highest internal temperatures of the mortars were measured as $24.00{ }^{\circ} \mathrm{C}, 23.90{ }^{\circ} \mathrm{C}$, 23.50, and $22.40{ }^{\circ} \mathrm{C}$, respectively (Figure 4). 


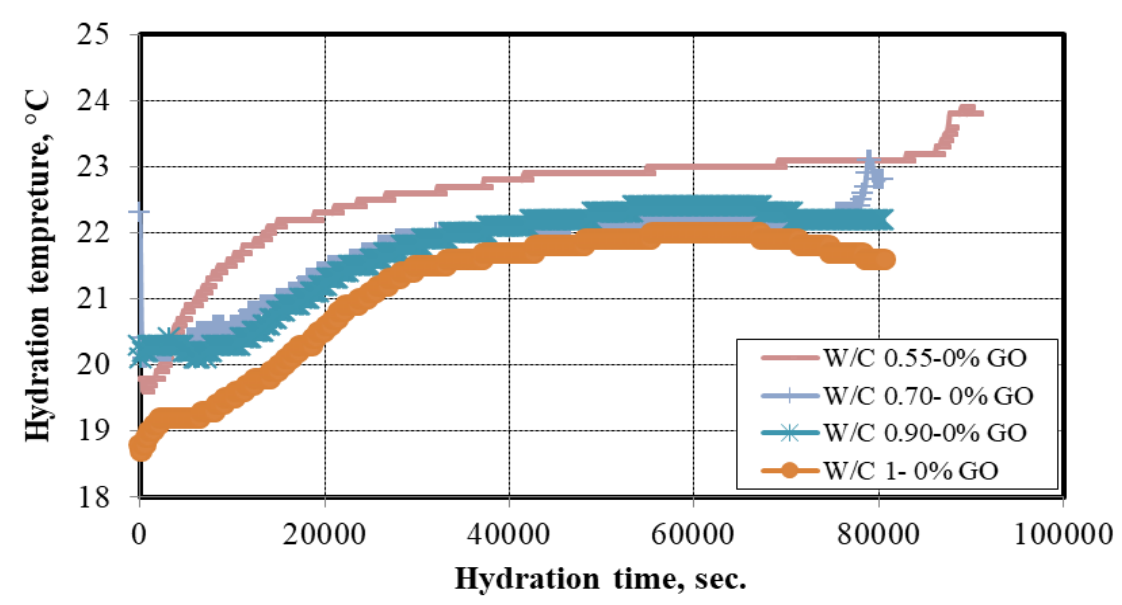

Figure 3. Internal temperature values of different water/cement ratios of mortars. Source: Self-Elaboration.

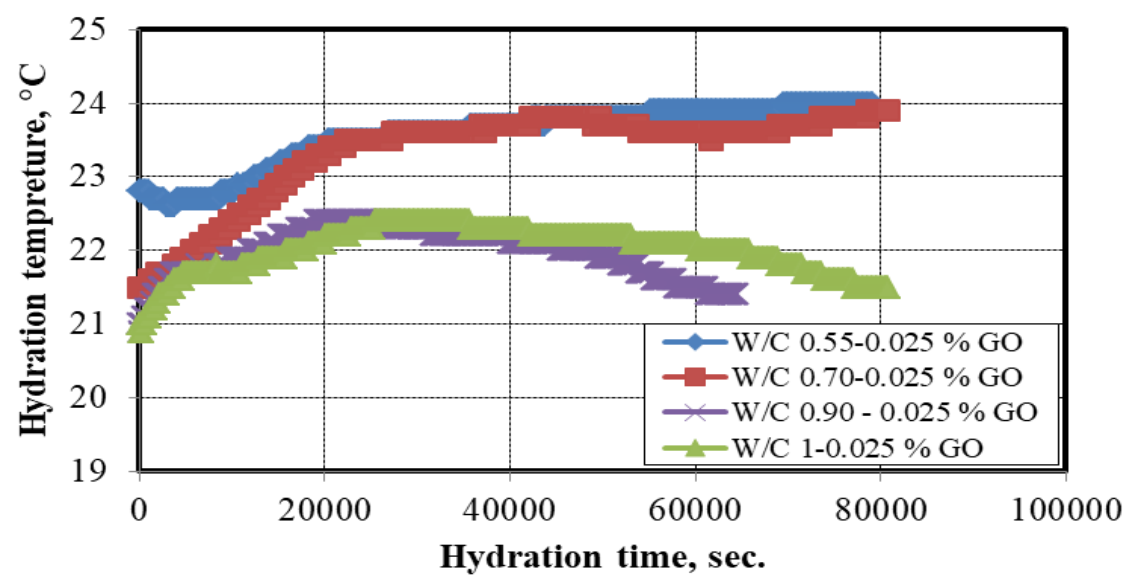

Figure 4. Internal temperature values of different water/cement ratios of mortars with $0.025 \%$ GO added.

Figure 5 was prepared to compare the hydration temperatures of mortars with different water-cement ratios $(0.55,0.70$, 0.90 , and 1.00 ), adding $0 \%$ and $0.025 \%$ GO. It was determined that with the addition of $0.025 \%$ GO in mortars with w/c ratios of $0.55,0.70$, and 1.00 , the maximum internal temperature of the mortar increased approximately $0.80{ }^{\circ} \mathrm{C}, 1.60$, and $0.40{ }^{\circ} \mathrm{C}$ (Figure 5). In mortars whose w/c ratio of 0.90 , although the maximum internal temperatures of the samples with and without GO have taken the same values, the first temperature measurement of the mortars without GO was measured as 20.30 ${ }^{\circ} \mathrm{C}$. The first temperature of which has GO sample was measured as $21.00{ }^{\circ} \mathrm{C}$. As a result, it was determined that by adding a small amount of GO to the mortars for all water/cement ratios, the internal temperature of the mortars generally increased and it is observed the hydration products occurred more quickly. 


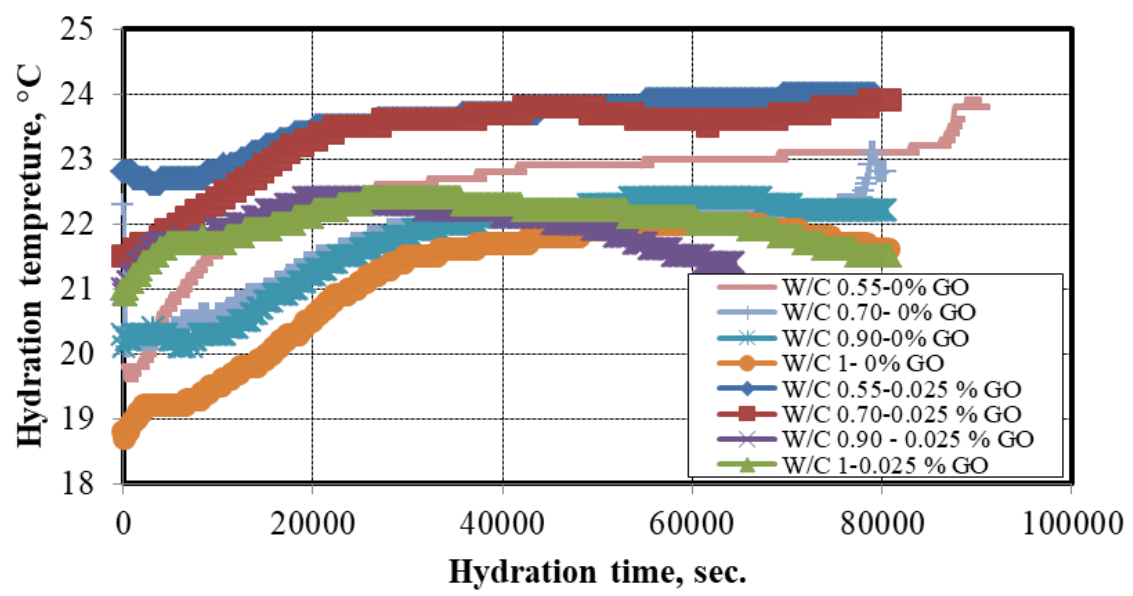

Figure 5. Internal temperature values of different water/cement ratios of mortars with $0.025 \%$ GO added and without GO. Source: Self-Elaboration.

Figure 6 and Figure 7 were prepared in order to investigate the effect of GO and 25 V DC application on mortar internal temperature in mortars with different w/c ratios. In mortars with $25 \mathrm{~V}$ stress intensity applied without GO, the highest internal temperature was obtained in the mixture with a w/c ratio of 0.90 (Figure 6).

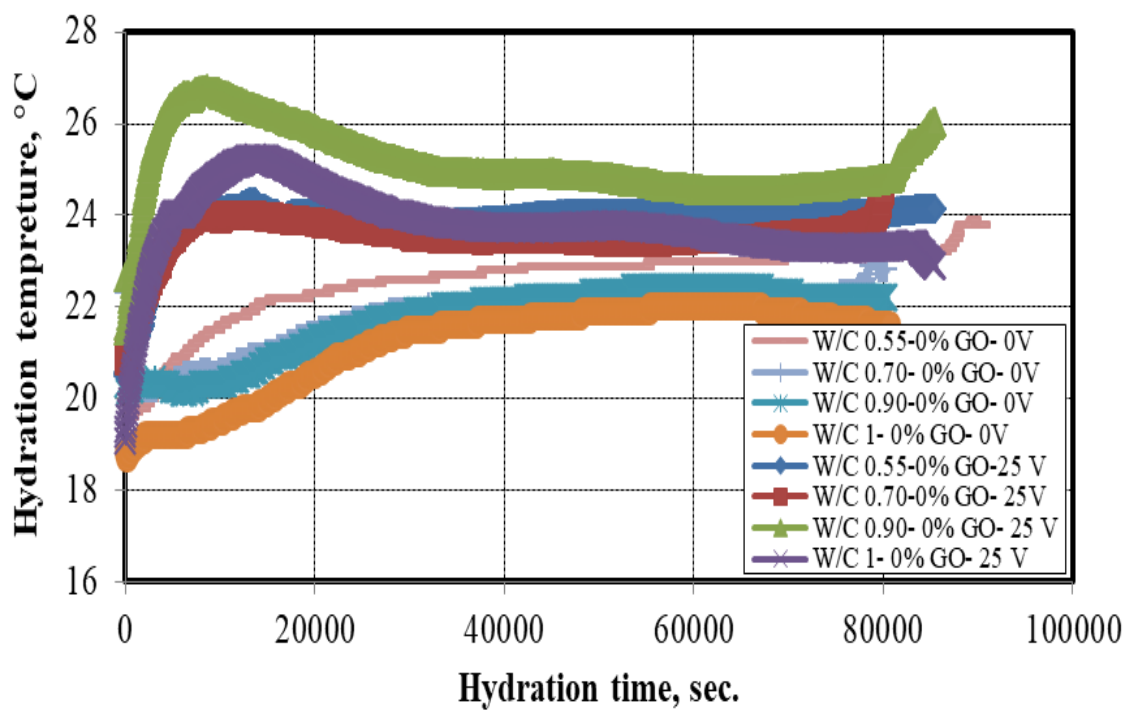

Figure 6. Internal temperature values of mortars depending upon water/cement ratios and DC application. Source: Self-Elaboration.

It has been observed that the internal temperatures of the mortar increase as the water/cement ratio decreases in the mortars where GO is added and current is not applied. As a result, by adding GO as low as 0.025 to the mortars, it can be interpreted that the internal temperatures of the mortars can self-heating, and hydration reactions can occur more quickly. It was observed that when both $0.025 \%$ GO was added to the mortars and $25 \mathrm{~V}$ (DC) stress intensity was applied, as the water/cement ratio increased, the internal temperature of the mortars increased too (Figure 7). As a result of this situation, $\mathrm{CSH}$ and $\mathrm{CH}$ gels, which are the products of hydration, can be formed faster by adding GO to the mortars and applying DC stress intensity, increasing the internal temperature of the mortar. 


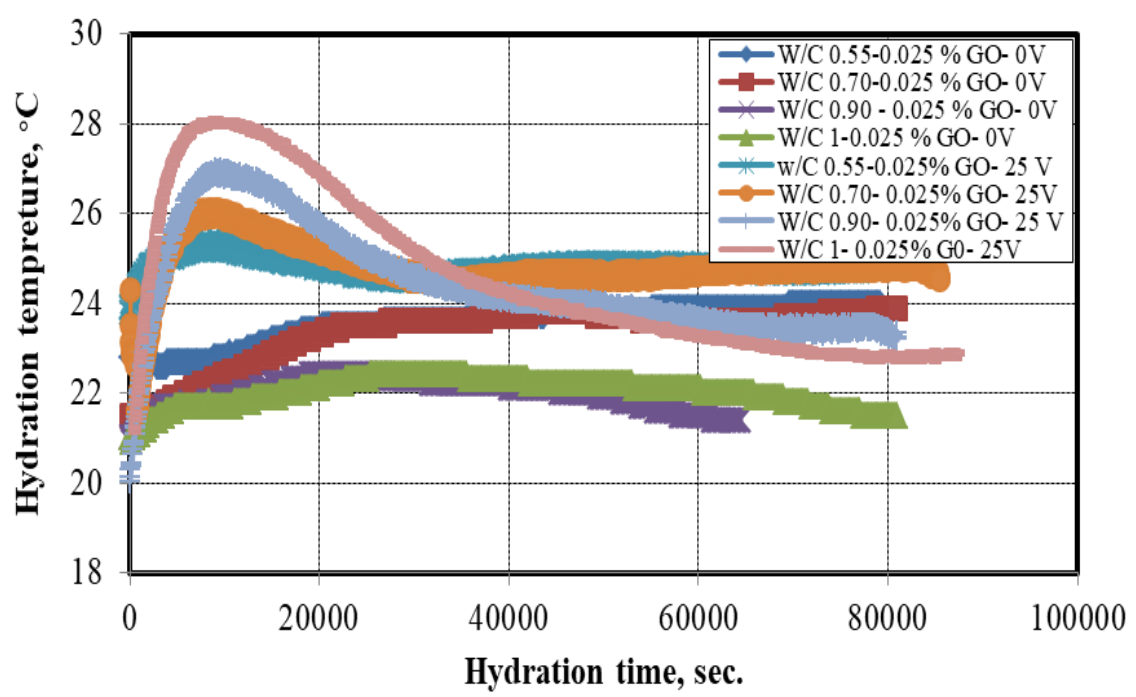

Figure 7. Internal temperature values of mortars depending upon w/c ratios-DC and GO. Source: Self-Elaboration.

When the internal temperature comparison is made, mortars to which stress intensity has applied; The internal temperatures of the mortars with GO for all water/cement ratios were observed higher than those without GO. In addition, it was observed that as the water/cement ratio increased in the reference samples to which direct current has applied, the internal temperatures of the mortars generally increased (Figure 8). Electrical conductivity occurs due to ion transport through the porous solution in a cement-based system and can be explained as the early stages depend on the water content of the cement matrix (Xiao et al., 2007; Schwarz et al., 2007; Heikal et al., 2005).

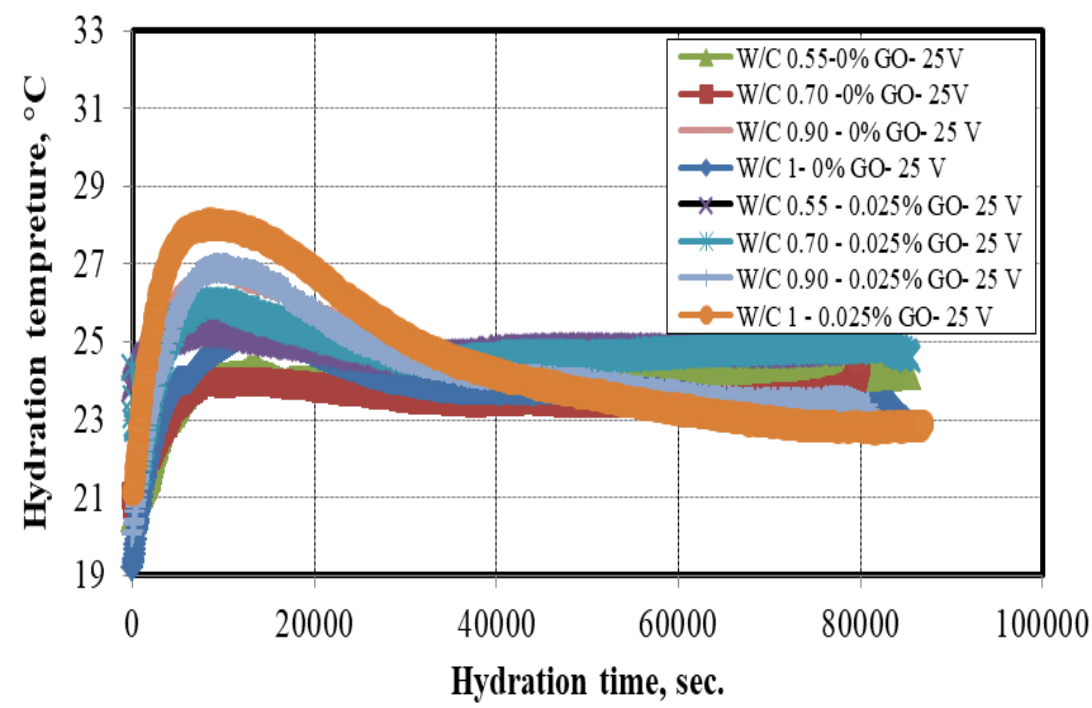

Figure 8. Internal temperature values of mortars depending upon w/c ratios-DC and GO.

To compare the maximum internal temperature of the mortars according to GO ratios, whether current is applied or not, and depending upon w/c proportions, Figure 9 has been drawn. In general, the maximum internal temperature of the mortars was measured between $20-25{ }^{\circ} \mathrm{C}$ degrees, while internal temperatures above $25{ }^{\circ} \mathrm{C}$ degrees were obtained by adding GO and direct current applied to the mortars. The maximum internal temperatures of the mortars with graphene oxide to which $0.55,0.70,0.90$, and $1.00 \mathrm{w} / \mathrm{c}$ ratios were measured as $25.35^{\circ} \mathrm{C}, 26.06{ }^{\circ} \mathrm{C}, 26.95$, and $28.09{ }^{\circ} \mathrm{C}$, respectively. It has seen that in mortars containing $0.025 \% \mathrm{GO}$ and $25 \mathrm{~V}$ (DC) stress intensity has applied, it is observed the highest internal 
temperature occurred in mortars whose water/cement ratio is 0.90. It is concluded that the electric current does not affect the internal temperature of the mortar at water/cement ratios higher than 0.90 in mortars to which have not to GO. In the sample with GO and DC current applied, the highest internal temperature was observed in mortars whose w/c ratio has 1.00. This situation can be explained by the fact that graphene oxide has the ability to absorb some water, and GO is electrically conductive.

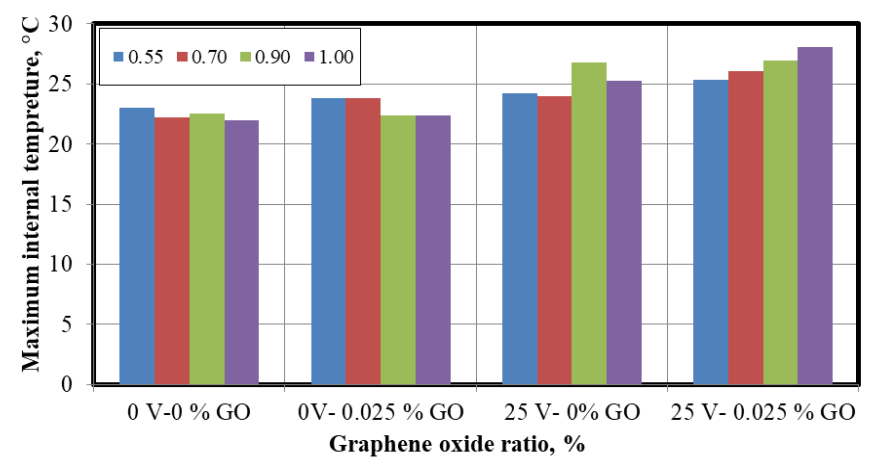

Figure 9. Maximum internal temperature values of different water/cement ratios of mortars. Source: Self-Elaboration.

\subsection{The impact of water/cement - GO ratio and DC current on final setting time}

Final setting times of the mortars with $0.55,0.70,0.90$ and, 1.00 water/cement ratios without GO and without current application were determined as 312, 313, 351 and 374 minutes, respectively. It has been seen that the final setting time of mortars whose w/c ratios 0.55 and 0.70 have occurred quicker than 0.90 and 1.00 water/cement mortars when current is not applied to mortars (Figure 10). When $0.025 \% \mathrm{GO}$ was added into the mortars, the final setting time increased by approximately 25 minutes in the mortar with a w/c ratio of 0.55 to which compared to the control samples. Increasing the final setting time by adding GO in the mortar with a w/c ratio of 0.55 can be explained by the absorption of some water by GO. In mortars to which w/c ratios have $0.70,0.90$ and, 1.00 , with the addition of $0.025 \%$ GO into each mortar, the final setting time was determined as approximately 37, 153 and, 198 minutes earlier, respectively (Table 3). When $25 \mathrm{~V} \mathrm{DC}$ current is applied to control samples (mortars without GO), to which water/cement ratios have 0.55, 0.70, 0.90 and, 1.00, the final setting time was determined as approximately 89,152, 206, and 119 minutes earlier, respectively. The fastest setting of the sample with 0.90 water/cement ratio to which $25 \mathrm{~V}$ DC current is applied could be explained by the takes highest internal temperature values of the mortar with $0.90 \mathrm{w} / \mathrm{c}$ ratio. When $25 \mathrm{~V}$ DC current is applied to which has $0.55,0.70,0.90$, and $1.00 \mathrm{w} / \mathrm{c}$ ratio that $0.025 \% \mathrm{GO}$ added on mortars, final setting times are shortened as 142, 174, 216, and 250 minutes, respectively. It is determined that the most suitable w/c ratio is 0.90 with and without GO. As a result of both increasing the water/cement ratio of till 0.90 and using GO in admixture and applying DC on mortars final setting times can be shortened.

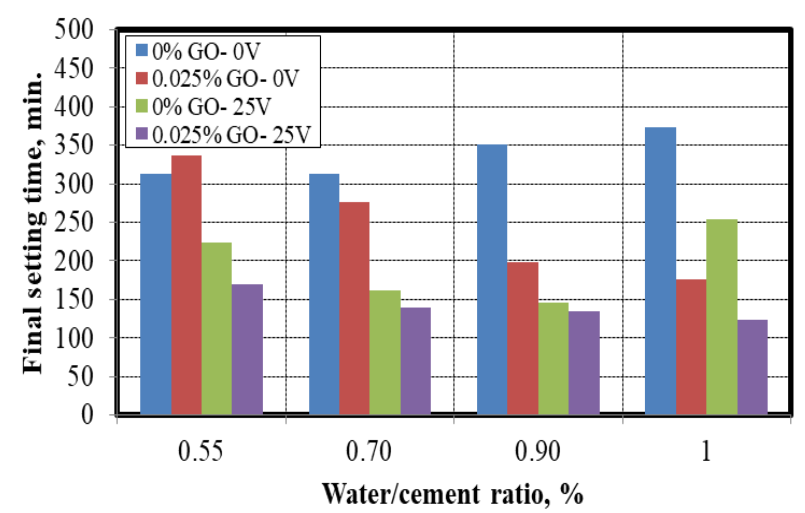

Figure 10. Final setting times of mortars according to w/c ratio - DC, and GO. 
Table 3. Final setting times of mortars according to grapheme oxide ratio and DC.

\begin{tabular}{ccccc}
\hline & \multicolumn{4}{c}{ Final setting time (min) } \\
\cline { 2 - 5 } W/c & 0V-0 \% GO & 0V- $0.025 \% \mathrm{GO}$ & $25 \mathrm{~V}-0 \% \mathrm{GO}$ & $25 \mathrm{~V}-0.025 \%$ GO \\
\hline 0.55 & 312 & 337 & 223 & 170 \\
\hline 0.70 & 313 & 276 & 161 & 139 \\
\hline 0.90 & 351 & 198 & 145 & 135 \\
\hline 1.00 & 373 & 176 & 254 & 123 \\
\hline
\end{tabular}

Final setting times of mortars depending upon DC, w/c ratio and GO can be calculated as Table 4.

Table 4. Final setting time equations and correlation modulus of mortars depending upon GO ratio and DC current.

\begin{tabular}{ccc}
\hline Current and GO ratio & Final setting time & $\mathrm{R}^{2}$ \\
\hline $0 \%$ GO 0V & $\mathrm{y}=381.82 \mathrm{x}^{2}-448.43 \mathrm{x}+442.22$ & $\mathrm{R}^{2}=0.9932$ \\
\hline $0.025 \%$ GO-0V & $\mathrm{y}=236.36 \mathrm{x}^{2}-731.59 \mathrm{x}+669.10$ & $\mathrm{R}^{2}=0,9980$ \\
\hline $0 \%$ GO-25 V & $\mathrm{y}=2024.2 \mathrm{x}^{2}-3111 \mathrm{x}+1328.6$ & $\mathrm{R}^{2}=0,8647$ \\
\hline $0.025 \% \mathrm{GO}-25 \mathrm{~V}$ & $\mathrm{y}=218.18 \mathrm{x}^{2}-430.18 \mathrm{x}+338.56$ & $\mathrm{R}^{2}=0,9230$ \\
\hline
\end{tabular}

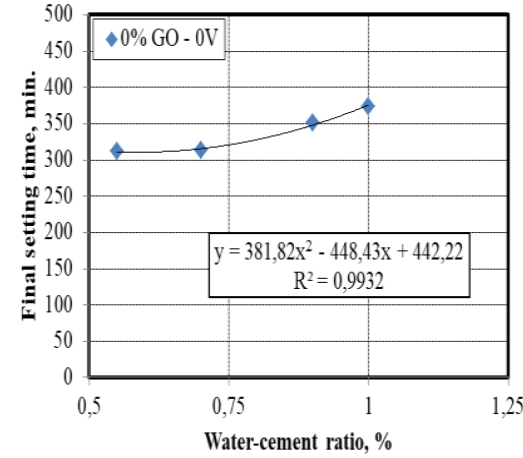

(a)

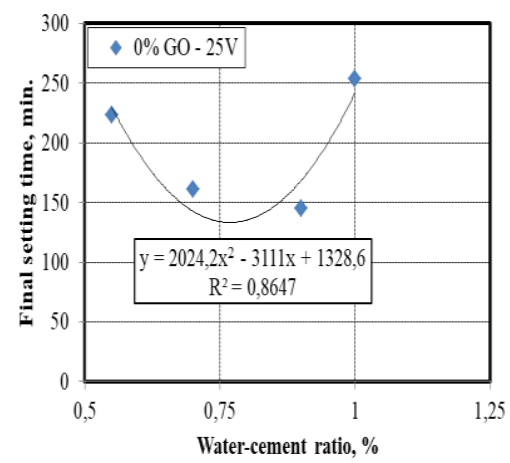

(c)

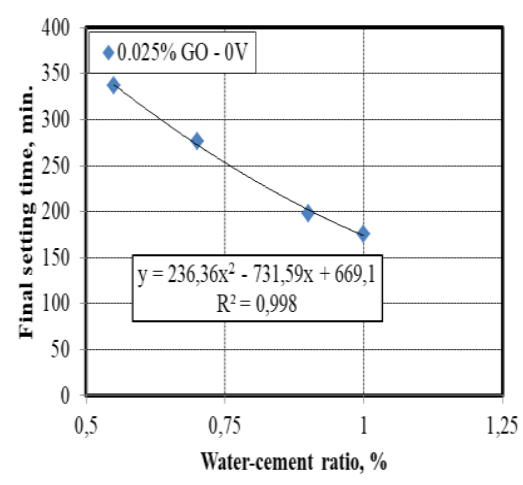

(b)

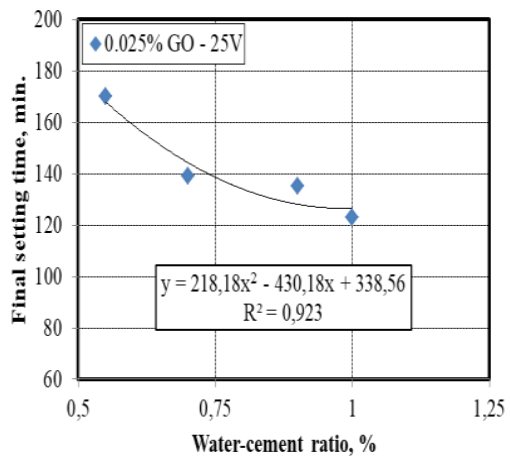

(d)

Figure 11. Final setting times of mortars depending upon w/c ratio a- 0 V-0\% GO, b- 0 V- $0.025 \%$ GO, c- 25 V- $0 \%$ GO, d- 25 V$0.025 \% \mathrm{GO}$.

\subsection{Results of flexural and compressive strength}

For searching flexural strength and compressive strength of mortars, Figure 12, Figure 13, and Figure 14 are prepared. When the 7-day flexural strength of the samples was compared, the samples with a w/c ratio of 0.90 in all series received the highest flexural strength values. It was observed that the samples with GO received more flexural strength values than the 
samples without GO. It has been observed that the 7-day flexural strength for all series decreases when the water/cement ratio rises above 0.90 .

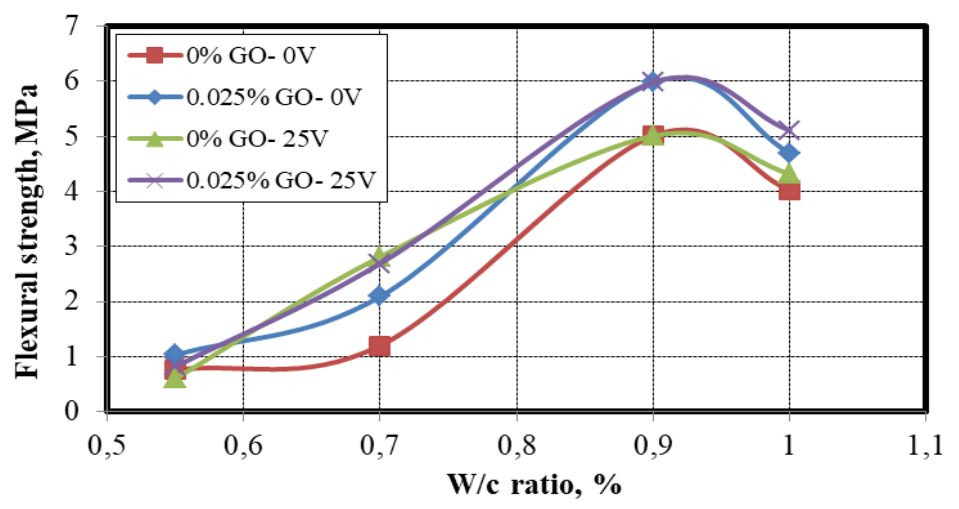

Figure 12. 7-day flexural strengths of mortars.

Figure 13 is drawn to compare the 28-day flexural strength of mortars. In general, higher flexural strength was obtained by adding GO and applying current to the mortars. For all series, the highest flexural strength was observed in mortars whose w/c ratio is 0.90. It has been observed that the flexural strength has increased with adding GO in mortars and DC stress intensity application. For example, by adding $0.025 \%$ GO to the mortars with a w/c ratio of 0.70 , it was observed that the flexural strength of the mortars for 28 days increased by approximately $12.59 \%$. It was observed that the 28 -day flexural strength increased approximately by $22.69 \%$ with the addition of GO for mortars that the same water/cement and with DC stress intensity application.

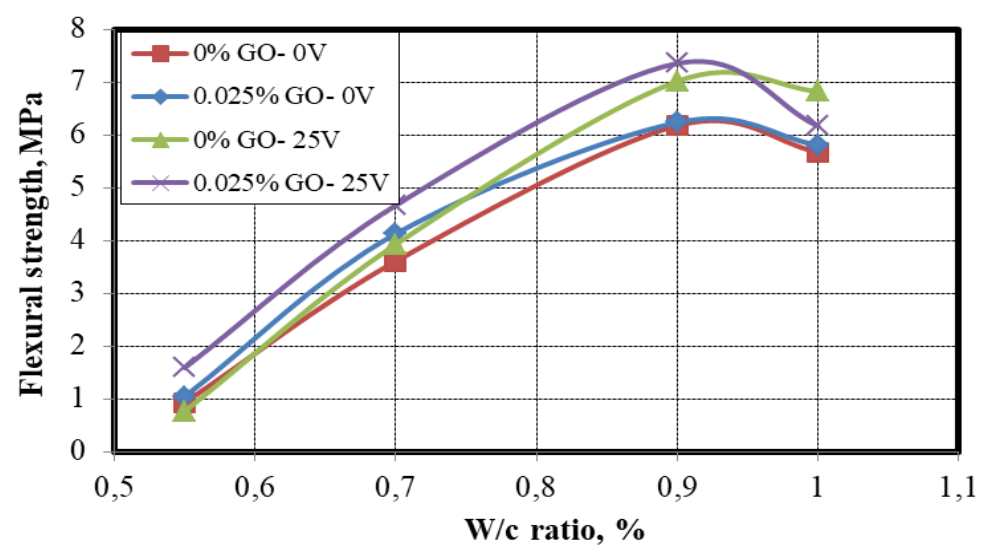

Figure 13. 28-day flexural strengths of mortars.

Figure 14 and Figure15 are drawn to compare the 7-day and 28-day compressive strength of mortars. The highest pressure values were obtained in mortars with a w/c ratio of 0.90 for 7-day and 28-day compressive strength. It has been observed that the compressive strength has increased with adding GO in mortars and DC stress intensity application. For example, by adding $0.025 \%$ GO to the mortars with a w/c ratio of 0.70 , it has been observed that the 28-day compressive strength of the mortars has increased by approximately $13.22 \%$. It was observed that the 28 -day compressive strength increased approximately by $17.04 \%$ with the addition of GO for mortars that the same water/cement and with DC stress intensity application. Kjaernsmo et al. (2018) observed that when $0.020 \%$ GO was added to the mortars, the compressive strength of the mortars for 28 days increased by approximately $15.00 \%$. Wang et al. (2019) concluded that by adding $0.030 \%$ GO to the mortars, an increase in compressive strength of approximately $21.37 \%$ could occur. 


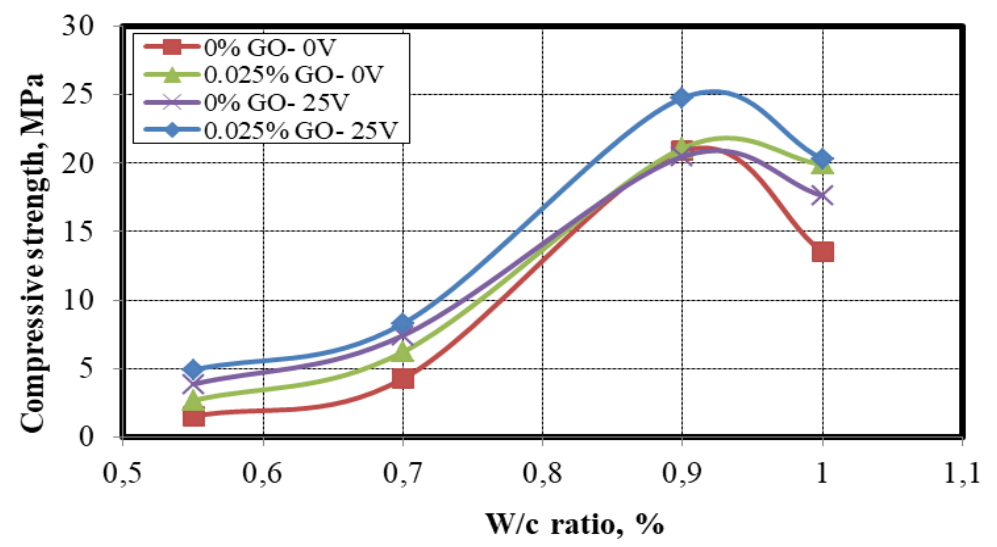

Figure 14. 7-day compressive strengths of mortars.

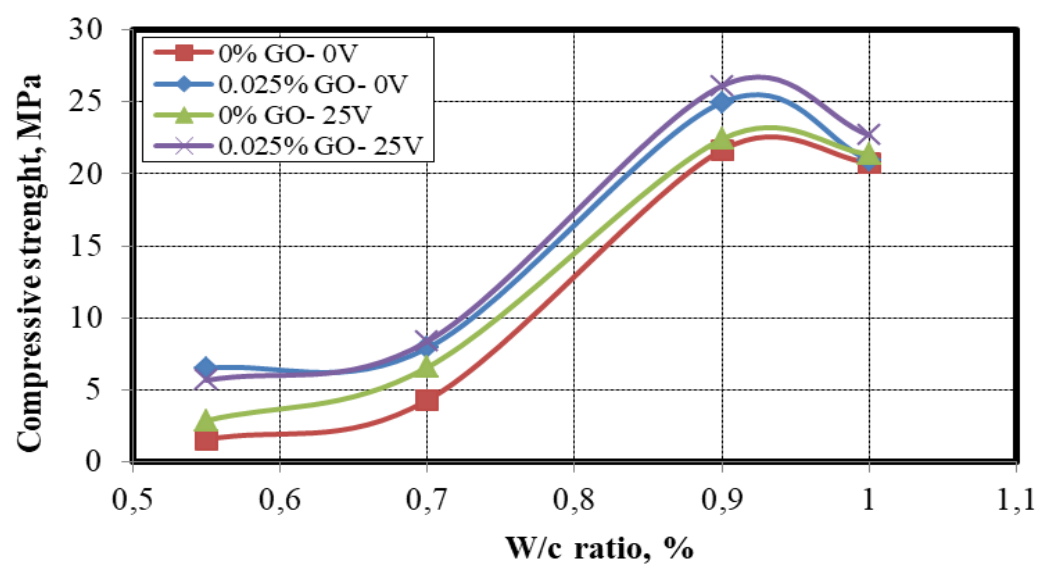

Figure 15. 28 day compressive strengths of mortars.

It was concluded that both the flexural strength and the 7-28-day compressive strength of the mortars could be increased by adding $0.025 \% \mathrm{GO}$ instead of cement into the mortars and the application of electric current.

\subsection{Micro examination of mortars}

During the hydration of cement-based materials immediately after mixing, calcium $(\mathrm{Ca})$ and hydroxyl $(\mathrm{OH})$ ions enter the solution within the first minutes (Wei \& Li, 2006). Then, as the calcium and hydroxyl ion concentrations rise slowly, nothing happens other than the slow precipitation of the semi-crystalline CSH gel (Buenfeld \& Newman, 1987; Li et al., 2007; Levita et al., 2000). The degree of hydration reaction is directly related to the hydration products in cement-based materials (Levita et al., 2000). 28-day microstructure photos of mortars that w/c ratios are 0.90 and to which $0 \mathrm{~V}, 25 \mathrm{~V}$ stress intensity is applied and depending upon GO (0-0.025 \%) ratio are shown in Picture 3. SEM (Scanning Electron Microscope) views are zoomed 10000 times. CSH and $\mathrm{CH}$ formed due to hydration reactions were seen in the reference mortars (Picture 3a). It is observed that hydration reactions become faster with DC current application. The reason for this situation can be explained as follows: with the current (DC) application on mortars, the speed of hydration and internal temperature of mortar increase. It has been observed that when $25 \mathrm{~V}$ stress intensity is applied on mortar, the hydration reactions occur quicker than mortars to which current is not applied (Picture 3b). It is observed that when GO is added to admixture on mortars, the CS and CSH gels have become faster (Picture 3c-d). Being a hydration product, CSH gels play the most important role in cement-based composites gaining strength and durability (Hu et al., 2014). The link between composition and mechanical properties can be explained by the mechanical and physical parameters of CSH gels ( $\mathrm{Hu}, 2014)$. Because most of the CSH gels are related to the $\mathrm{CSH} / \mathrm{CH}$ composite group (Hu, 2014). The most effective elements in the formation of CSH gels are calcium (Ca) and Silicon (Si). The 
higher $\mathrm{Ca} / \mathrm{Si}$ ratios of $\mathrm{C}-\mathrm{S}-\mathrm{H}$ gels indicate that other phases are also formed $(\mathrm{Hu}, 2014)$. When the stress intensity on the mortar was increased from $0 \mathrm{~V}$ to $25 \mathrm{~V}$, it was determined that the $\mathrm{Ca} / \mathrm{Si}$ ratio in the admixture was increased. (Table 5). EDS views of mortars have shown in Figure 16.

Table 5. EDS (energy dispersive spectrum) of mortars depending upon DC and GO ratio.

\begin{tabular}{cccccccc}
\hline & \multicolumn{9}{c}{ Chemical analysis (\%) } \\
\hline GO (\%) and stress intensity (V) & $\mathrm{O}_{2}$ & $\mathrm{Mg}$ & $\mathrm{Al}$ & $\mathrm{Si}$ & $\mathrm{S}$ & $\mathrm{Ca}$ & $\mathrm{Ca} / \mathrm{Si}$ \\
$0 \% \mathrm{GO}-0 \mathrm{~V}$ & 72.22 & 0.73 & 2.19 & 8.82 & 0.72 & 32.81 & 3.71 \\
$0.025 \% \mathrm{GO}-0 \mathrm{~V}$ & 63.58 & 0.44 & 1.41 & 8.85 & 0.86 & 37.66 & 4.25 \\
$0 \% \mathrm{GO}-25 \mathrm{~V}$ & 73.14 & 1.29 & 3.28 & 4.20 & 1.64 & 34.49 & 8.21 \\
$0.025 \% \mathrm{GO}-25 \mathrm{~V}$ & 76.03 & 0.20 & 0.91 & 4.06 & 0.50 & 37.09 & 9.13 \\
\hline
\end{tabular}

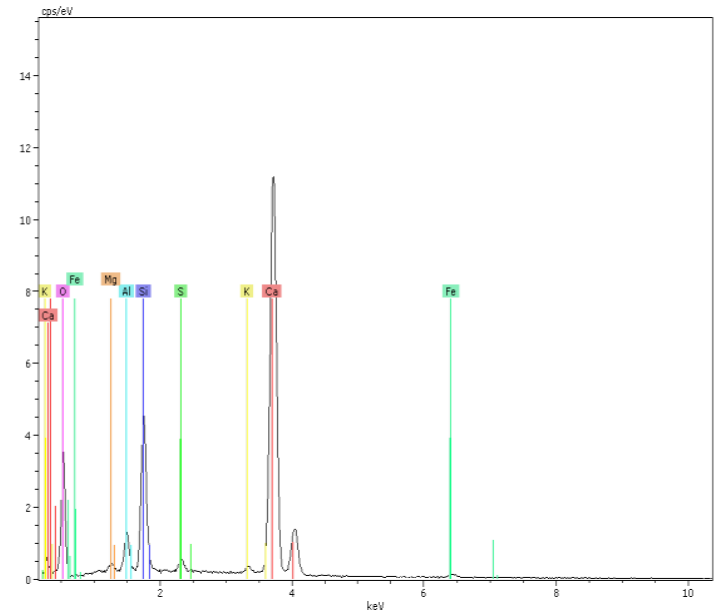

(a)

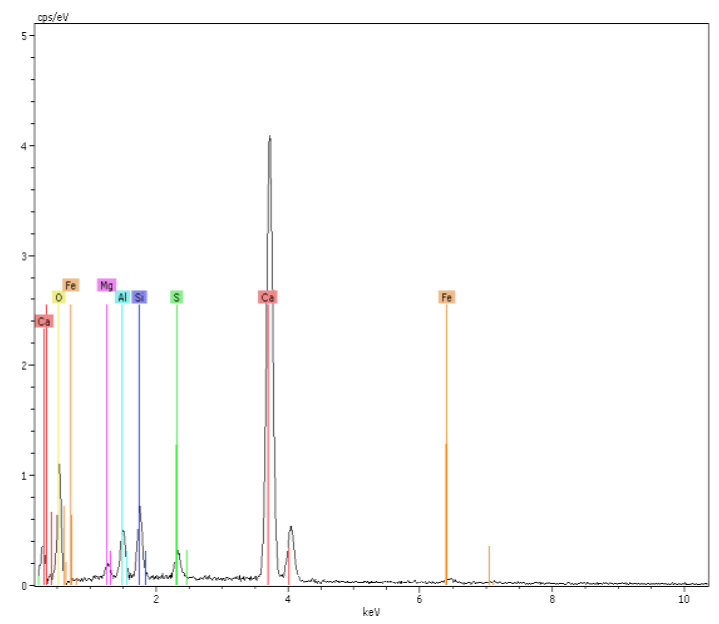

(c)

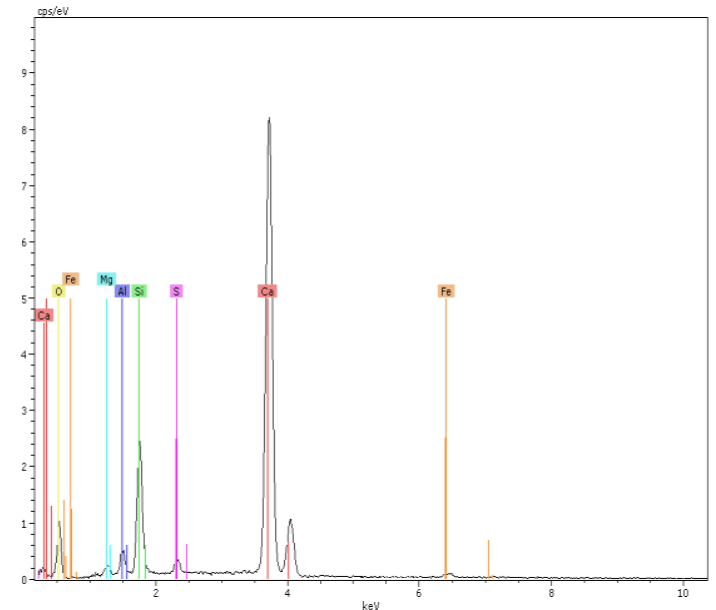

(b)

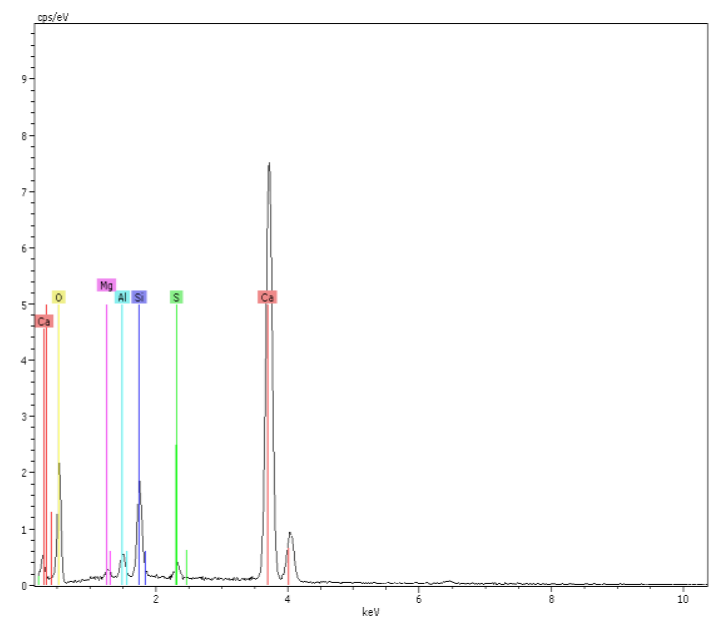

(d)

Figure 16. EDS views of mortars (a) 0V-0 \% GO; (b) 0V- $0.025 \%$ GO; (c) 25V- $0 \%$ GO; (d) 25V- $0.025 \%$ GO. 


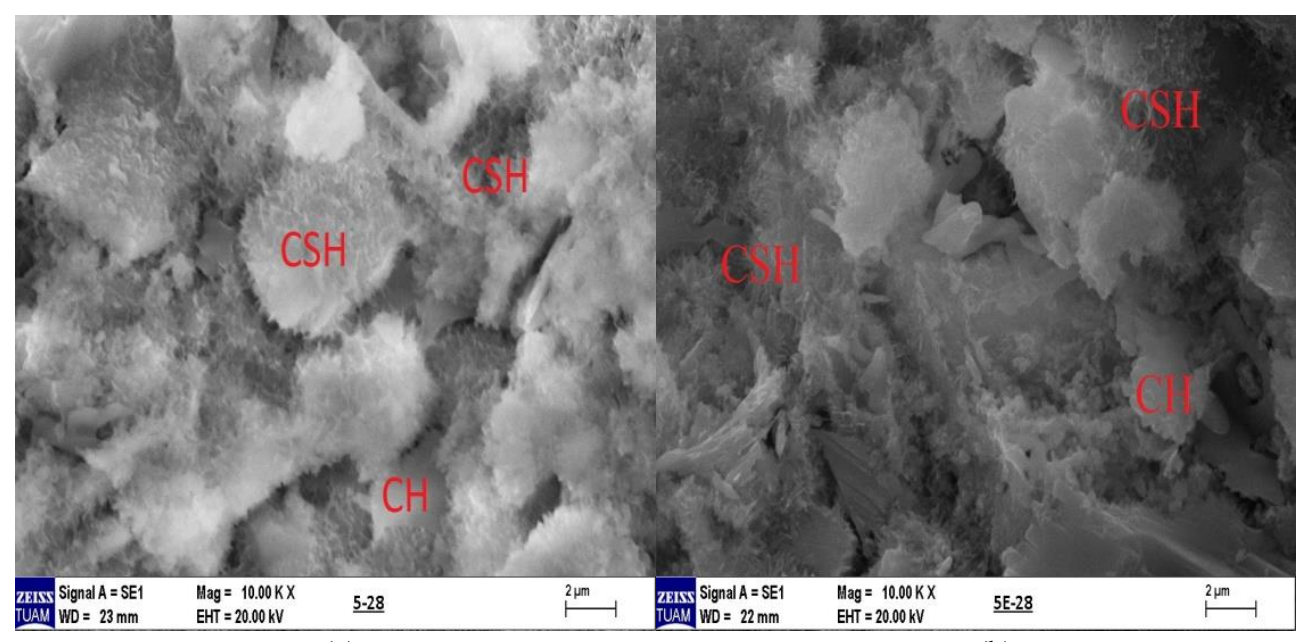

(a)

(b)

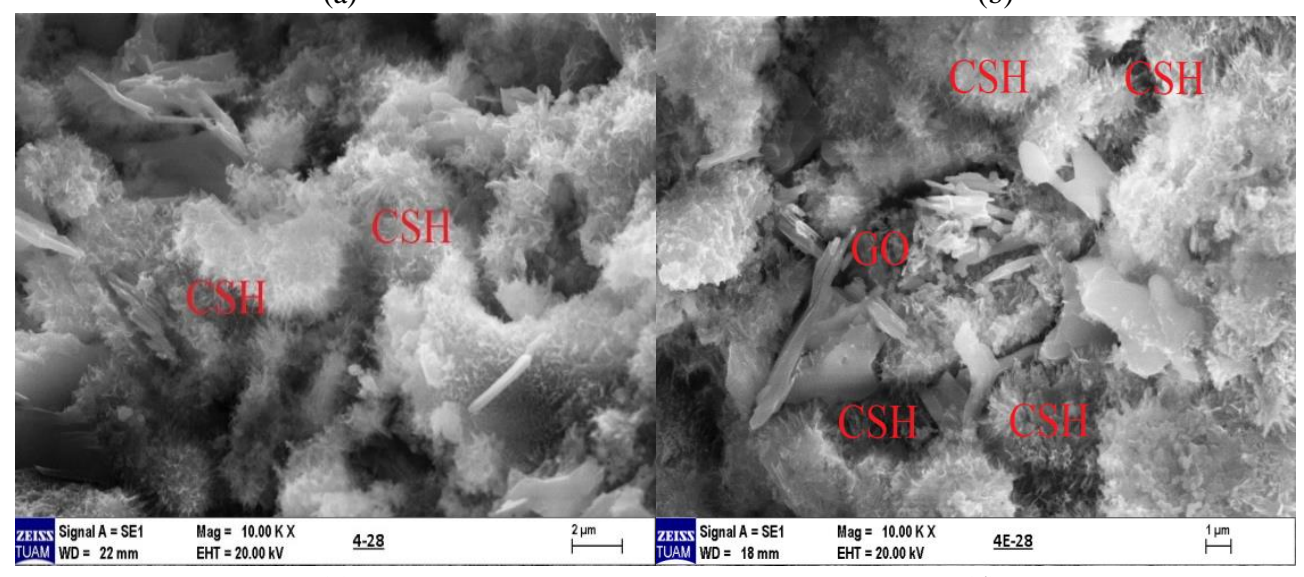

(c)

(d)

Figure 17. Microstructure photos of mortars (a) 0 V-0 \% GO; (b) 25 V- $0 \%$ GO; (c) 0 V- $0.025 \%$ GO; (d) 25 V- $0.025 \%$ GO.

The XRD patterns of hydration crystals depending on GO (0.025\%) and direct current (25V) application whose water/cement ratio is 0.90 are shown in Figure 16. It is seen that hydration products increase with adding GO and applying direct current on mortars.

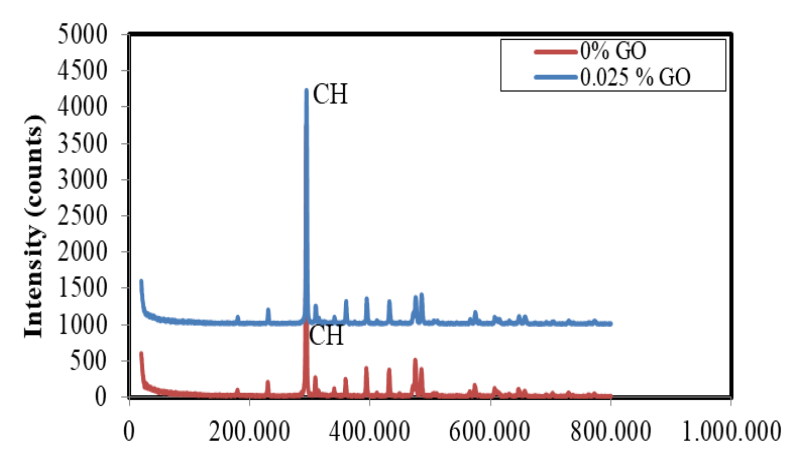

2Theta (Coupled TwoTheta/Theta) WL=1.54060

(a)

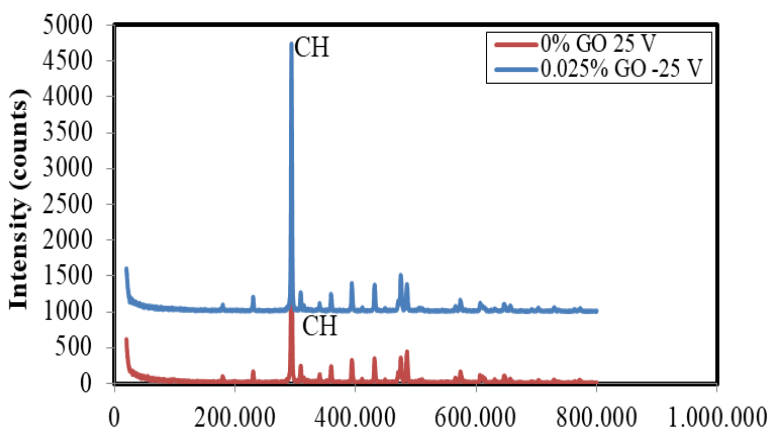

2Theta (Coupled TwoTheta/Theta) WL=1.54060

(b)

Figure 18. XRD patterns of hardened mortars depending on GO and DC application. 


\section{Conclusions and comments}

Nanotechnology products such as graphene oxide provide innovation in cement-based mortars and concrete by adding a new vision to building materials. Increasing the internal temperature of the nanomaterial to be used in cement-based mortars by itself can be used to improve the strength and durability properties of the mortars. This investigation is important for cement-based materials that require quick repair. The results obtained in the research are explained below:

1. It was concluded that both the flexural strength and the 28-day compressive strength of the mortars can be increased by adding $0.025 \% \mathrm{GO}$ instead of cement into the mortars and the application of electric current.

2. As a result of XRD analysis, it is seen that hydration products increase with adding GO and applying DC on mortars.

3. It is observed that when $25 \mathrm{~V}$ direct current is applied on mortar, the hydration reactions occur quicker than the mortar to which current is not applied.

4. It is determined that the most suitable w/c ratio is 0.90 with and without GO.

5. As a result of both increasing the w/c ratio of till 0.90 and using GO in admixture and applying DC on mortars, final setting times can be shortened.

6. It is seen that when $\mathrm{GO}$ is added to admixture on mortars, the hydration reactions have become faster.

7. Mortars with w/c ratios of $0.70,0.90$, and 1.00 respectively, by adding $0.025 \%$ GO and applying $25 \mathrm{~V}$ DC stress, the final setting times are approximately 37, 153, and 198 minutes, respectively, shortened.

8. As a rusult by adding $\mathrm{GO}$ as low as 0.025 to the mortars, it can be interpreted that the internal temperatures of the mortars can self-heating, and hydration reactions can occur more quickly.

Although graphene oxide is a very expensive material, positive physical and mechanical results can be obtained even with a small amount of $0.025 \%$ (by weight instead of cement) addition in cement-based composite materials. This research can be improved through applying different stress intensities (DC), alternative current (AC), and adding different amounts of graphene oxide on different dosage mortars. The effects of graphene oxide on concrete should also be investigated.

Author contributions: Dr. İsmail Hocaoğlu conducted the experiments, interpreted them, and wrote the article.

Conflicts of interest: There are no conflicts of interest.

References

Akarsh, P.K., Bhat A.K. (2021). Graphene oxide incorporated concrete for rigid pavement application. In Lecture Notes in Civil Engineering, Springer Singapore, 99, 199-219. https://doi.org/10.1007/978-981-15-6828-2_16

Alkhateb, H., Al-Ostaz, A., Cheng, A. H.-D., \& Li, X. (2013). Materials Genome for Graphene-Cement Nanocomposites. Journal of Nanomechanics and Micromechanics, 3(3), 67-77. https://doi.org/10.1061/(asce)nm.2153-5477.0000055

Alma, H., M. Yazici, B. Yildirim, B. Salan, I. Tiyek. (2017), Coating and characterization of nano-sized graphene on spunbond nonwoven textile surface by electro drawing method. Textile and Engineer, 24 (108) 243-253. https://doi.org/10.7216/1300759920172410803

ASTM. (2015). Estimating Concrete Strength by the Maturity Method. Astm C1074.

Buenfeld, N. R., \& Newman, J. B. (1987). Examination of three methods for studying ion diffusion in cement pastes, mortars and concrete. Materials and Structures, 20(3). https://doi.org/10.1007/BF02472720

Chen, S. J., Collins, F. G., Macleod, A. J. N., Pan, Z., Duan, W. H., \& Wang, C. M. (2011). Carbon nanotube-cement composites: A retrospect. IES Journal Part A: Civil and Structural Engineering, 4(4), 254-265. https://doi.org/10.1080/19373260.2011.615474

Chintalapudi, K., Mohan, R., Pannem, R. (2020). An intense review on the performance of graphene oxide and reduced graphene oxide in an admixed cement system. Construction and Building Materials, 259, 598-618. https://doi.org/10.1016/j.conbuildmat.2020.120598

Du, H., \& Pang, S. D. (2015). Enhancement of barrier properties of cement mortar with graphene nanoplatelet. Cement and Concrete Research, 76, 10-19. https://doi.org/10.1016/j.cemconres.2015.05.007

EN 197-1. (2011). Cement. Composition, specifications and conformity criteria for common cements. European Standard.

Heikal, M., Morsy, M. S., \& Aiad, I. (2005). Effect of treatment temperature on the early hydration characteristics of superplasticized silica fume blended cement pastes. Cement and Concrete Research, 35(4), 680-687. https://doi.org/10.1016/j.cemconres.2004.06.012 
Hu, C. (2014). Microstructure and mechanical properties of fly ash blended cement pastes. Construction and Building Materials, 73, 618-625. https://doi.org/10.1016/j.conbuildmat.2014.10.009

Hu, C., Han, Y., Gao, Y., Zhang, Y., \& Li, Z. (2014). Property investigation of calcium-silicate-hydrate (C-S-H) gel in cementitious composites. Materials Characterization, 95, 129-139. https://doi.org/10.1016/j.matchar.2014.06.012

Jing G.J., Ye, Z.M., Li, C., Cui, J., Wang, S.X., Cheng, X. (2019). A ball milling strategy to disperse graphene oxide in cement composites. Xinxing Tan Cailiao/New Carbon Materials, 34(6), 569-677. https://doi.org/10.1016/S1872-5805(19)60032-6

Jing, G., Ye, Z., Lu, X., \& Hou, P. (2017). Effect of graphene nanoplatelets on hydration behaviour of Portland cement by thermal analysis. Advances in Cement Research, 29(2), 63-70. https://doi.org/10.1680/jadcr.16.00087

Kjaernsmo, H., Kakay, S., Fossa, K.T., Gronli, J. (2018). The effect of graphene oxide on cement mortar, International Conference on Smart Engineering Materials, 362, 120-132. https://doi.org/10.1088/1757-899X/362/1/012012

Levita, G., Marchetti, A., Gallone, G., Princigallo, A., \& Guerrini, G. L. (2000). Electrical properties of fluidified Portland cement mixes in the early stage of hydration. Cement and Concrete Research, 30(6), 923-930. https://doi.org/10.1016/S0008-8846(00)00282-9

Li, X., Korayem, A. H., Li, C., Liu, Y., He, H., Sanjayan, J. G., \& Duan, W. H. (2016). Incorporation of graphene oxide and silica fume into cement paste: A study of dispersion and compressive strength. Construction and Building Materials, 123, 327-335. https://doi.org/10.1016/j.conbuildmat.2016.07.022

Li, Z., Xiao, L., \& Wei, X. (2007). Determination of Concrete Setting Time Using Electrical Resistivity Measurement. Journal of Materials in Civil Engineering, 19(5), 423-427. https://doi.org/10.1061/(asce)0899-1561(2007)19:5(423)

Lu, L., \& Ouyang, D. (2017). Properties of cement mortar and ultra-high strength concrete incorporating graphene oxide nanosheets. Nanomaterials, 7(7), 187-201. https://doi.org/10.3390/nano7070187

Luo, Y., Gan, Y., Xu, J., Yan, Y., Shi, Y. (2017). Effect of electric field intensity and frequency of AC electric field on the small-scale ethanol diffusion flame behaviors, Applied Thermal Engineering, 115, 1330-1336. https://doi.org/10.1016/j.applthermaleng.2016.11.145

Makar, J. M., \& Chan, G. W. (2009). Growth of cement hydration products on single-walled carbon nanotubes. Journal of the American Ceramic Society, 92(6), 1303-1310. https://doi.org/10.1111/j.1551-2916.2009.03055.x

Pan, Z., He, L., Qiu, L., Korayem, A. H., Li, G., Zhu, J. W., ... Wang, M. C. (2015). Mechanical properties and microstructure of a graphene oxide-cement composite. Cement and Concrete Composites, 58, 140-147. https://doi.org/10.1016/j.cemconcomp.2015.02.001

Peyvandi, A., Soroushian, P., Balachandra, A. M., \& Sobolev, K. (2013). Enhancement of the durability characteristics of concrete nanocomposite pipes with modified graphite nanoplatelets. Construction and Building Materials, 47(5), 111-117. https://doi.org/10.1016/j.conbuildmat.2013.05.002

Sanchez, F., \& Sobolev, K. (2010). Nanotechnology in concrete-A review. Construction and Building Materials, $24,2060-2071$. https://doi.org/10.1016/j.conbuildmat.2010.03.014

Schwarz, N., DuBois, M., \& Neithalath, N. (2007). Electrical conductivity based characterization of plain and coarse glass powder modified cement pastes. Cement and Concrete Composites, 29, 656-666. https://doi.org/10.1016/j.cemconcomp.2007.05.005

Shuya, B., Linhua, J., Yu, J., Ming, J., Shaobo, J., Debiao, T. (2020). Research on electrical conductivity of graphene/cement composites. Advances in Cement Research, 32(2), 45-52. https://doi.org/10.1680/jadcr.16.00170

Singh, A. P., Mishra, M., Chandra, A., \& Dhawan, S. K. (2011). Graphene oxide/ferrofluid/cement composites for electromagnetic interference shielding application. Nanotechnology, 22(46), 46-57. https://doi.org/10.1088/0957-4484/22/46/465701

Sobolev, K., Shah, S.P. (2015). Nanotechnology in construction, Proceedings of NICOM5. Chicago USA, 3-13. https://doi.org/10.1007/978-3-319-17088-6

Tiyek, I., Yazici, M., Alma, M. H., Donmez, U., Yildirim, B., Salan, T., Karteri, I. (2016). Characterisation of poly (acrylonitrile-vinyl acetate) / graphene oxide nanofiber structures | Nanolif yapili poli (akrilonitril-vinil asetat)/ grafen oksit yapilarin karakterizasyonu. Tekstil ve Muhendis, 23(102), 81-92. https://doi.org/10.7216/1300759920162310201

Tomlinson, D., Moradi, F., Hajiloo, H., Ghods, P., Alizadeh, A., \& Green, M. (2017). Early age electrical resistivity behaviour of various concrete mixtures subject to low temperature cycling, 83, 323-334. Cement and Concrete Composites. https://doi.org/10.1016/j.cemconcomp.2017.07.028

Uygunoglu, T., Topçu, I. B., Çinar, E., \& Resuloğullari, D. (2019). Electrical and mechanical properties of historical mortars in Bursa/Turkey. Revista de La Construccion, 18(1), 54-67. https://doi.org/10.7764/RDLC.1.1.54

Wade, S. A., Nixon, J. M., Schindler, A. K., \& Barnes, R. W. (2010). Effect of Temperature on the Setting Behavior of Concrete. Journal of Materials in Civil Engineering, 22(3), 214-222. https://doi.org/10.1061/(asce)0899-1561(2010)22:3(214)

Wang, Y., Yang, J., \& Ouyang, D. (2019). Effect of graphene oxide on mechanical properties of cement mortar and its strengthening mechanism. Materials, 12(22), 2-18. https://doi.org/10.3390/ma12223753

Wei, X., \& Li, Z. (2006). Early Hydration Process of Portland Cement Paste by Electrical Measurement. Journal of Materials in Civil Engineering, 18(1), 99-105. https://doi.org/10.1061/(asce)0899-1561(2006)18:1(99) 
Xiao, L. zhen, Li, Z. jin, \& Wei, X. sheng. (2007). Selection of superplasticizer in concrete mix design by measuring the early electrical resistivities of pastes. Cement and Concrete Composites, 29, 350-356. https://doi.org/10.1016/j.cemconcomp.2006.12.015

Xu, Z., \& Gao, C. (2011). Aqueous liquid crystals of graphene oxide. ACS Nano, 5(4), 2908-2915. https://doi.org/10.1021/nn200069w

\section{(1) $\Theta \Theta$ \\ BY NC ND}

No Derivatives 4.0 International License. 